\title{
REVIEW. FRAILE-MARCOS ANA MARIA. ED. 2014. LITERATURE AND THE GLOCAL CITY: RESHAPING THE ENGLISH CANADIAN IMAGERY. NEW YORK: ROUTLEDGE INTERDISCIPLINARY PERSPECTIVES ON LITERATURE. PP. 181. ISBN: 978-1-138-77563-3
}

\author{
Vicent Cucarella Ramón, Universidad de Valencia ${ }^{1}$ \\ Email: Vicent.Cucarella@uv.es
}

The distinctive trait that has come to signify and shape the Canadian identity has been for so long shilled by a myth of wilderness that eventually configured a genuine nationalism understood in terms of Nature. However, ranging from the 1960s, and as a consequence of an unyielding process of globalization, the city has taken central stage within the Canadian imaginary as a pivotal site where the conflicting tenets of the kaleidoscopic nature that define the multilayered and interconnected world intersect. Taking this into account, the volume Literature and the Glocal City: Reshaping the English Canadian Imagery, edited by Ana María Fraile-Marcos, offers an interdisciplinary coupling of articles by a group of noted Canadianists that revolve around the Canadian city as an academic and cultural outlet through which it is possible to delve and analyze the politics of representation that delineate the ethos of the Canadian nation-state.

Thus, the main goal of the book is to propound the contemporary Canadian city as a fruitful critical axe able to surmount a fresh and new analysis of Canada so that it can live up to the cultural challenges of our global era. In the substantial and utterly impassioned introduction, Ana María Fraile-Marcos dwells on the concept of 'urban glocality', as an intersection of both global and local scales, to voice and "engage with urban and globalization studies, as well as with literary theory and criticism" (Fraile-Marcos, 2014: 3) that can contour the representation of Canada. In addition, as Fraile-Marcos contends, the focus on 'urban glocality' applies to problematize over "oppositional critical discourses as postcolonialism, diaspora, feminism, multiculturalism, and environmentalism" (Fraile-Marcos, 2014: 3 ) that continue to hold a seminal place in the definition of the contested Canadian distinctiveness. Accordingly, the space emerges as the central paradigm where the global and the local interject to get converted into "the scenario for the struggle against the nefarious effects of neoliberal globalization" (Fraile-Marcos, 2014: 3) that ultimately affects and alters the understanding of Canada in national terms. Hence, despite the oxymoronic nature that the term 'glocal' exhales it has developed into a valuable critical tenet to expose the multiple cultural faces of the Canadian culture and its literary production. By accepting

Date of reception: 11 March 2015

Date of acceptance: 20 April 2015 
a certain balance between the global forces and the local sense, and precisely because of the entrenchment of either concepts, the notion of 'glocaliy' is proposed in the book as a profitable theoretical framework to revisit the Canadian imaginary and for the "redefinition of citizenship in the context of a profoundly mobile world that nevertheless maintains and reinforces social, economic, cultural, and political boundaries" (Fraile-Marcos, 2014: 7).

Following the introduction, the book is divided into ten chapters that account to render various visions of different artistic representations within the scope of the Canadian imaginary sharing the perspective of the glocal city as the referent point.

In chapter number one, entitled "Mobility and Its Disenchantments in Marie Clements' The Unnatural and Accidental Women and Burning Vision”, Deena Rymhs offers a picture of a glocal Vancouver pinpointing the racialization of space linked to the racial, colonial and gendered violence impinged upon Indigenous women as well as the nefarious outcome that the technologies of mobility have played in contemporary societies. In Burning Vision the focus is global whilst in The Unnatural and Accidental Women there is a local vision and yet both plays explore the intimacies of violence in the context of a neoliberal and capitalist era. Rhyms analyzes both plays by weaving the global through the local and viceversa just to attempt a critical approach that reimagines spaces posing the notion of a smaller world without boundaries.

In the second chapter, "Embodying the Glocal: Immigrant and Indigenous Ideas of Home in Tessa McWatt's Montreal", Michèle Lacombe reads McWatt's novel Out of My Skin as an exploration of the co-existence of different racialized epistemologies aiming to hold postcolonial and Indigenous subjectivities together within the scope of Montreal as a glocal city. Drawing on the 1990 Oka 'crisis' that defined the Indigenous resistance to thwart the Canadian state from building a golf course on the burial grounds of the Kanesaki First Nation, Lacombe shows how the local and the global merge in McWatt's novel swiftly to lay out a repressed colonial past that swings between the former British and French feuds to expose the wounds that are still open in globalized societies in which the glocal approach aims to endorse a healthier version of multiculturalism.

Coral Ann Howells' third chapter, "From Romanwood to Downtown: The Torontonians and Girls Fall Down", stems from the post-1960s feminist discourse to highlight a feminized view of Toronto reshaped into an unhomely glocal spot whereby an apocalyptic and disquiet nature challenges the notions of compassion, human respect and social justice that pave the way for the penetration of international threats such as global terrorism that configures a spatial anxiety and unease due to the complexity and diversity of the glocal city.

The speculative fiction is at the core of Belén Martín-Lucas' fourth chapter, entitled "Dystopic Urbanites: Civilian Cyborgs in TransCanadian Speculative Fictions". In it Martín-Lucas relies on the science fiction and fantasy of Nalo Hopkinson's Brown Girl in the Ring and Larissa Lai's Salt Fish Girl to delve into the effects of the neoliberal, globalized, and transnational hubs of Toronto and Vancouver respectively. Both novels seem to render a form of communalism with the purpose to outlive the crisis of multiculturalism as well as to get beyond the zombification of capitalism to eventually celebrate the triumph of utopian urban subjects that emerge from the shambles of the dystopic city.

In chapter number five, "The Intrinsic Potential of Glassness: Narcissistic, Opaque, Organic Modes of Signifying the Urban in Vancouver", Eva Darias-Beautell focuses on 
four works attuned to the approach of urban semiotics to configure the city as a locus whereby urban history is enmeshed in the collective memory of contemporary Vancouver. Analyzing the semiotics of a novel, a collection of short stories, a catalogue of photographs, and a poetry collection, Darias-Beautell considers the symbol of glass -common to the four works- as a malleable glocal space that reveal the intricate dynamics of the social and economic dimensions of globalism.

In line with Darias-Beautell's essay, Ana María Fraile-Marcos offers a semiological approach in her reading of Michael Helm's multilayered novel Cities of Refuge in chapter number six. Thus, in "The Refugee as Signifier in the Semiotics of the Glocal City: Michael Helm's Cities of Refuge", Fraile-Marcos submits the role of the asylum seeker as a signifier that challenges the binaries of the semiotics to foster a glocal space where to reflect upon the threats that globalization and neoliberalism pose with regard to concepts such as security, hospitality, humanitarianism, or international peacekeeping that have historically been incorporated to the national ethos of Canada.

Chapter number seven is entitled "Responding to Late Capitalism: The Mall". In it, Kit Dobson draws on urban architecture to reconsider the impact of human alienation that the late capitalism has imposed in the demise of the suburban mall. The urban glocalization of the malls, in which the ideologies of neoliberalism surface, bring about a sense of malaise and nostalgia as a cultural response that the mall, reshaped into an actual and imagined space, attempts to encapsulate in Canada.

Following Edward Soja's discussion of glocalization, with his prominent concept of 'synekism' that deals with human proximity and agglutination, chapters eight and nine provide essays by Brandon McFarlane and Herb Wyle, respectively, that engage a debate over the forces of neoliberalism within the Canadian publishing industry. McFarlane presents a glocal city understood as a postmetropolis in which hipsters have synthesized the local and the global simply to adopt an anti-establishment slant that aims at the shattering of the polarized view of the Canadian identity. The glocality of the aesthetics of hipsterdom serves McFarlane to read their approach to Canadian literature as a tool to claim a national belonging based upon geographic continuity as opposed to a disputed historical or ethnic tradition. In tune with McFarlane, Wyle focuses on Michael Winter's The Architects Are Here highlighting how the forces of synekism in the novel capture a vision of the city that stretches from the rural to the urban to embrace the global. The entanglement of such forces, Wyle proposes, reminds us that the focus of Canadian literature and Canadian literary criticism have budged towards the city that attests to alter into a network of strands where the global and the local become entangled to critique the dictations of neoliberalism.

The last chapter by George Elliott Clarke, titled "Ian Fleming's Canadian Cities", centers on the oeuvre of spy novelist Ian Fleming to offer a vision of Canada from the perspective of the foreign writer. Clarke argues that Fleming has traditionally eyed Canada as a site of multicultural cities although he scathingly questions his "pro-Anglo-imperialist fantasy" (Fraile-Marcos 2014: 162) that makes the British author shape Canadian identity in the wilderness rather than in the country's cities as the glocal scheme would rather suggest.

In sum, by proposing to read through the lens of the notion of urban glocality the book makes a highly interesting intervention in English Canadian literary criticism to set forth a revision and a cultural reconfiguration of terms such as multiculturalism, transnationalism 
and globalization. In such a way, the publication adds up to George Grant's seminal 1965 book, Lament for a Nation: The defeat of Canadian Nationalism, Frank Davey's Post-National Arguments: The Politics of the Anglophone Canadian Novel since 1967 (1993), and Michael Byers' Intent for a Nation: What is Canada for? (2007) in the attempt to rethink the aesthetics of Canadian cultural environment while filling in the gap of new literary approaches linking the city and globalization. Focusing on the conflicting tensions that outline the relationships between local, regional, national and global forces in the context of the glocal city, this collection of essays endeavors to negotiate new understandings of political and cultural discourses as well as to intercede into the national imaginary and idiosyncratic transformation of the Canadian nation-state.

The wide range of approaches and proposals that can be found in Literature and the Glocal City: Reshaping the English Canadian Imagery call to account a national culture that outreaches the limits of the nation-state but which, at the same time, refuses to give up on the nation and succeeds at shedding new light on the field of urban studies and bring the Canadian literary experience to the fore making it an all the more essential reference manual to anyone interested in Canadian studies.

\section{REFERENCES}

Byers, M. 2007. Intent for a Nation: What is Canada for? Vancouver: Douglas \& McIntyre.

Davey, F. 1993. Post-National Arguments: The Politics of the Anglophone Canadian Novel since 1967. Toronto: U. of Toronto P.

Grabt, G 2005. Reprint. Lament for a Nation: The defeat of Canadian Nationalism (1965). Quebec: McGill-Queen's University Press. 